\title{
Neurociencias, educación y salud mental
}

\author{
Neuroscience, education and mental health
}

\author{
Manuel Arboccó de los Heros ${ }^{1 a}$ \\ ${ }^{1}$ Universidad Inca Garcilaso de la Vega, Lima, Perú.
}

\begin{abstract}
aPsicólogo y psicoterapeuta, director del Instituto de Investigación de la Facultad de
Psicología de la Universidad Inca Garcilaso de la Vega. Docente universitario.
\end{abstract}

Recibido: 22-09-15

Aprobado: 23-11-15

\section{Correspondencia}

Email: manoloarbocco@gmail.com

\section{Citar como:}

Arboccó de los Heros, M. (2016). Neurociencias, educación y salud mental. Propósitos y Representaciones, 4(1), 327-362. doi:http:// dx.doi.org/10.20511/pyr2016.v4n1.92

(c) Universidad San Ignacio de Loyola, Vicerrectorado de Investigación y Desarrollo, 2016. (c) BY-NC-ND Este artículo se distribuye bajo licencia CC BY-NC-ND 4.0 Internacional (http://creativecommons.org/licenses/by-nc-nd/4.0/). 


\section{Resumen}

El siguiente artículo presenta una serie de investigaciones, reflexiones y citas sobre las Neurociencias, la Educación y la Psicología. Áreas cada una especializada en ciertas materias, pero que en algún momento se encuentran y comparten territorio, se nutren entre ellas y nos ayudan a entender -cada vez más-el complejo mundo del aprendizaje, el cerebro y el comportamiento humano. Esperamos que sea de interés y dé impulso a nuevas reflexiones.

Palabras clave: Neurociencias, cerebro triuno, neuronas espejo, aprendizaje, lectura, salud mental, sentido del humor.

\section{Summary}

The following article presents a series of investigations, reflections, and quotes about neuroscience, education, and psychology. Each area is specialized in some matters but at some point they share territory and mutually benefit one another, and help us to increasingly understand the complex world of learning, the brain, and human behavior. We hope them to be of interest and a promoter of new thoughts.

Keywords: Neuroscience, triune brain, mirror neurons, learning, reading, mental health, sense of humor. 


\section{Introducción}

\section{Las neurociencias y el homo sapiens.}

Siempre se nos ha dicho que el hombre es el homo sapiens, el hombre que sabe, el hombre sabio. Olvidan, los que eso dicen, que el hombre por naturaleza (y por cronología evolutiva) primero siente y luego piensa. Es un "hombre sentidor", emocional antes que sabio. Lo vemos tanto en la historia de la humanidad como en el desarrollo ontológico de cada ser humano. Primero se siente (miedo, alegría, cólera, dolor), y luego irán apareciendo los procesos cognitivos superiores, como la imaginación, el análisis, la deducción y la razón.

Si vemos esto desde las neurociencias, campo en feliz desarrollo, estas nos han informado de los distintos cerebros que tenemos. Paul MacLean (1913-2007), famoso neurólogo estadounidense, notició del cerebro triuno, conformado por el cerebro reptil, que regula los elementos básicos de supervivencia; el cerebro paleomamífero, que comprende el sistema límbico -y resultado de ello son las experiencias emocionales-, y el cerebro neomamífero, la neocorteza que nos permite la interpretación de lo acontecido y la toma de decisiones pensadas. A diferencia de la gran mayoría de los mamíferos inferiores, el ser humano tiene los tres.

La teoría del cerebro triuno concibe la persona como un ser constituido por múltiples capacidades interconectadas y complementarias; de allí su carácter integral y holístico que permite explicar el comportamiento humano desde una perspectiva más integrada, donde el pensar, sentir $\mathrm{y}$ actuar se compenetran en un todo que influye en el desempeño del individuo, tanto en lo personal y laboral como en lo profesional y social. (Velásquez et al., 2006, p. 232).

Investigaciones hechas en laboratorios demuestran que las áreas cerebrales más ligadas a la humanidad y al comportamiento civilizado tienen 
relación directa con el lóbulo frontal, encargado del juicio, el control de impulsos y la planificación, entre otras funciones, y estas zonas aparecen activadas mayormente a medida que crecemos; por el contrario, en el niño y en el adolescente hay un predominio de zonas límbicas (LeDoux, 1999). Un dato adicional: algunos estudios documentan haber encontrado que en el cerebro de asesinos en serie y en esquizofrénicos hay daños en zonas frontales y prefrontales (Gil Verona, 2002).

El hecho de crecer, aprender, socializar y madurar guarda una relación con el buen desempeño cerebral y, en especial, con las zonas del neocórtex. Asimismo, se está investigando cómo la violencia verbal y psicológica estaría retrasando el desarrollo normal de nuestro cerebro durante la infancia (MesaGresa, 2011). Tiene mucho sentido, ya que infantes y niños así lastimados tienen luego dificultades para el autocontrol, el aprendizaje y el equilibrio emocional. Las neurociencias dan luz en el interesante y complejo mundo psicológico.

\section{Cerebro masculino y cerebro femenino.}

Los estudios científicos han venido dando algo de luz en el complicado mundo de los sexos y las relaciones de género. Intentar explicar ciertas diferencias entre hombres y mujeres ha sido la tarea de psicólogos, sociólogos, antropólogos, así como sexólogos y, ahora, neurocientíficos (Ledoux, 1999; Iacoboni, 2009).

Vemos cómo existen marcadas predisposiciones mentales y conductuales según el género. Así, por ejemplo, la hiperactividad infantil y la afasia (dificultades con el lenguaje) se dan más en niños que en niñas; la depresión, por su parte, la padecen mayormente las mujeres; la esquizofrenia, el autismo y el trastorno de personalidad psicopático se dan más en varones (Aamodt \& Wang, 2008; Bragdon \& Gamon, 2005). ¿Por qué ocurren situaciones como las mencionadas?, ¿mala suerte?, ¿el destino?, ¿los astros? 
Por supuesto que no. La ciencia, y en especial las neurociencias, están brindando respuestas por lo demás interesantes. Respuestas que no descartan (y muchas veces se complementan) otras de tipo familiar, sociocultural (aprendizaje, trato, costumbres).

Hace algunas décadas se comprobó que el cuerpo calloso (región que une ambos hemisferios cerebrales) es más grueso y más grande en las mujeres que en los hombres. Se descubrió que las mujeres emplean ambos hemisferios para casi todo y que el cerebro del hombre produce testosterona desde que está en el vientre de la madre, esto es, desde que es un feto. Además, el hipotálamo tiene casi el doble del tamaño en hombres que en mujeres.

Siguiendo con estas tendencias, observamos que la emocionalidad y la organización suelen ser femeninas, mientras que la violencia y la corrupción son mayormente masculinas. Las mujeres tienen mejor memoria emocional, mientras que los hombres salen mejor en pruebas de razonamiento matemático y tareas mecánico-espaciales. El hombre está más capacitado para la concentración en una sola tarea a la vez; por su parte, la mujer puede realizar más tareas simultáneamente. El tema es largo, pero estos son solo algunos ejemplos (Ledoux, 1999; Santana Martinez, 2010; Aamodt \& Wang, 2008).

No se propone con esto, como erróneamente se podría creer, que un sexo es mejor que el otro o que determinadas cualidades o problemas son exclusivos de ellos o de ellas. Por el contrario, conocernos mejor, tanto a nivel mental y sexual como comportamental, es de gran ayuda en el proceso de desarrollo personal y de convivencia social. 


\section{El hallazgo de las neuronas espejo.}

En el año 1996, los neurocientíficos italianos Giacomo Rizzolatti, Leonardo Fogassi y Vittorio Gallese, quienes estaban estudiando la planificación y el control motor, colocaron electrodos en el cerebro de un mono. Notaron que, cuando uno de estos animales observaba a otro realizar una acción, algunas de sus neuronas (del área motora) reaccionaban. Cuentan que, al principio, pensaron que era un error de medición o un fallo en el equipo. Al verificar que todo estaba bien, se encontraron con un enorme descubrimiento científico.

Entonces, casi de casualidad, como ocurren también muchos descubrimientos importantes, hallaron un grupo de neuronas conocidas como las neuronas espejo o neuronas especulares. Se denomina así a cierta clase de neuronas que se activan cuando un animal o una persona observa una acción realizada por un semejante. Es decir, basta observar a otro haciendo algo para que, de manera similar a lo que sucede en su cerebro, en el nuestro también se activen esas neuronas implicadas. Tales neuronas habían sido observadas, en primer lugar, en primates; luego se encontraron en algunas aves y, de la misma forma, en los seres humanos (Iacoboni, 2009).

En estudios posteriores se pudo constatar que las neuronas espejo no solo se activan cuando vemos a alguien realizar determinada acción, sino que es suficiente con que lo imaginemos; por ejemplo, cuando nos imaginamos haciendo algo como trepando un árbol. Parece que, hasta cierto punto, el cerebro no diferencia lo que es real de lo que es producto de la imaginación.

El hallazgo de las neuronas espejo permite ahora entender por qué cuando vemos a otros bostezar o reír o llorar, existe una suerte de "conexión emocional" (cuando la hay) con estas personas, terminando en una especie de "contagio" que reproduce en nosotros aquellas conductas (también bostezamos, reímos y, de pronto, lloramos). 
Este descubrimiento del campo de las neurociencias permite tener una mejor explicación evolutiva y cerebral para una serie de aspectos como el aprendizaje, la imitación, la identificación y la empatía, entre otros, tan importantes para la vida y, sobre todo, para la vida social. Es probable también que estos circuitos de neuronas no se activen o que se activen deficientemente en los psicópatas, en los esquizofrénicos, en los autistas y retrasados mentales más graves (Iacoboni, 2009; Santana Martinez, 2010). Las neurociencias nos siguen brindando respuestas.

\section{EI libro y el celular.}

Proponemos el siguiente ejercicio. Acérquenle a un(a) niño(a) pequeño(a) un libro y un celular, y fijense por cuál de los dos se inclina el pequeño. Lo más probable es que termine eligiendo el celular, lo cual no tiene nada de raro al ser un aparato que permite la interacción, tiene efectos sonoros, brinda imágenes y juegos. Es aquí donde el adulto ingresa en escena. Como adultos y personas racionales, sabemos que el principal aspecto que necesita la humanidad en su proceso de formación es la palabra, el verbo, la argumentación. La lectura y luego la escritura son tareas exclusivamente humanas que nos permiten adaptarnos, socializar y solucionar muchos problemas. Y como adultos buscamos que, desde pequeños, los humanos aprendan la importancia de leer y el placer de hacerlo, situación que nos permitirá acercarnos a la civilización, el entendimiento y la cultura. Pero, hoy, los niños tienen desde muy temprana edad -algunos ya desde bebésacceso al celular, la tablet y la TV, y aprenden a emplearlos mucho antes que a leer, y vemos que sus cerebros se están acostumbrando a no leer, con lo que puede verse limitada su imaginación, su desarrollo verbal, su capacidad de análisis y de ordenar las ideas (Sartori, 2004).

En una reciente entrevista periodística al escritor y profesor universitario Jorge Eslava, nos recuerda que "una buena lectura es una experiencia de inteligencia e imaginación. También de sensibilidad. Creo 
que desarrollar la lectura desde niños cultiva y modela el espiritu”" (Eslava, 2015 , p. 7). Por su parte, para la psicóloga y escritora Pilar González Vigil, "la lectura desarrolla la imaginación de los niños, y ahora se sabe, gracias a las investigaciones en el campo de las neurociencias, que nuestro cerebro no diferencia entre lo que imaginamos y lo que experimentamos en la realidad. Entonces, en su mente los lectores viven la historia junto a los personajes" (González Vigil, 2015, p. 7). En estos dos comentarios encontramos cómo formar el hábito de la lectura es fundamental en las personas, y como todo buen hábito, debe ser formado desde pequeño. Porque el niño solo no lo hará; él se dirigirá hacia el celular (que se lo prestan siempre que lo pide) o hacia la TV (que se la encienden a toda hora), cuando de pronto tendríamos que acercarlo creativa, divertida y amorosamente al texto, al libro. La lectura (sobre todo su práctica desde pequeños) promueve el ejercicio de la atención, la imaginación, la creatividad, potencia el pensamiento abstracto y el desarrollo del lenguaje (Beltrán \& Seinfeld, 2012). Hay quienes ven también que la lectura nos lleva a aprender muchas otras cosas, a ser más tolerantes, y nos da lecciones morales inclusive. Por su parte, el polígrafo Marco Aurelio Denegri la considera "el único vicio saludable”. Dice así: "Se trata, empero, de una medicina que, curiosamente, satisface un vicio; solo que un vicio saludable, el único vicio saludable: el de la lectura" (Denegri, 2011, p. 70).

\section{Consume peruano, consume.}

Desde tecnología que no necesitas hasta programas de TV que te idiotizan.

"El peligro del pasado era que los hombres fueran esclavos. Pero el peligro del futuro es que los hombres se conviertan en robots"

Erich Fromm

"El mundo actual es un mundo Popeye", nos dice el psicólogo Claudio García Pintos en su texto La vida es una moneda. Así: 
La fuerza viene en forma de lata de cerveza, pastillas para dormir, para tener mayor vigor sexual, teléfonos de ultimísima generación y automóviles espectaculares que marcan mi nivel social, etc. Creemos ser lo que tenemos, lo que ostentamos, lo que hacemos. Compramos, consumimos, tomamos, pero la aguja sigue sin ser encontrada. (García Pintos, 2010, p. 90).

Por tanto, el hombre actual (niño o adulto) consume y consume nimiedades, y ocurre algo curioso: se hace adicto a estas y ya no puede, en adelante, consumir menos de ellas; necesita igual o mayor cantidad para no padecer el respectivo síndrome de abstinencia y, así, seguirá embotado. Se dice que nadie está obligado a dejar de hacer lo que la ley no prohíbe, y como no hay ley que prohíba adormecer o embrutecer a la gente o esparcir porquería, como lo hacen muchos de los medios de comunicación (sobre todo cuando la gente misma lo aprueba: léase rating), entonces el circuito nefasto continúa. En un trabajo anterior (Arboccó \& O’Brien, 2012) hemos investigado este punto. Detrás existen mezquinos intereses, monopolios y grupos de poder, así como una nula conciencia social. Conviene tener a la masa (de votantes, de lectores, de televidentes, de radioescuchas) adormecida, confundida, idiotizada, ignorante y temerosa; así serán más manejables, así serán "menos peligrosos". Ya estamos viendo el bajo nivel de comprensión lectora que ostentan los muchachos hoy en día. Cierto es que este problema tiene varias causas.

Recordemos, finalmente, una reflexión de Mario Vargas Llosa en La civilización del espectáculo:

La adquisición obsesiva de productos manufacturados, que mantengan activa y creciente la fabricación de mercancías, produce el fenómeno de la "reificación" o "cosificación" del individuo, entregado al consumo sistemático de objetos, muchas veces inútiles o superfluos, que las modas y la publicidad le van imponiendo, vaciando su vida interior de inquietudes sociales, espirituales o simplemente humanas, aislándolo y destruyendo su conciencia de los otros, de su clase y de sí mismo. (Vargas Llosa, 2012, p. 16). 


\section{El homo videns.}

"Vivimos la cultura de la incultura"

Giovanni Sartori

En su texto Homo videns: la sociedad teledirigida (2004), el politicólogo italiano Giovanni Sartori analiza el peligro de exponer a los niños (el los llama los video-niños) ante la televisión basura, y nos deja una serie de afirmaciones y estadísticas que bien pueden ser tomadas en cuenta en muchas realidades sociales, las mismas que están debidamente planteadas y fundamentadas en la obra mencionada. Por ejemplo, indica que el niño ensimismado con la TV no lee; la TV modifica radicalmente y empobrece el aparato cognoscitivo del homo sapiens; el niño formado en la imagen se reduce a ser un hombre que no lee; luego, ese adulto sólo responderá a estímulos audiovisuales (Sartori, 2004). Además, nos recuerda que el acto de ver está atrofiando la capacidad de entender, que el hombre que lee está decayendo rápidamente, y lo peor de todo es que (en este mundo actual pareciera que) "ya no se necesita leer".

Sartori señala investigaciones indicando que un joven, antes de terminar su adolescencia, habrá observado horas y horas de telebasura (Sartori, 2004). Ese niño luego se transformará en un adulto empobrecido, que no lee, que responde a estímulos casi exclusivamente audiovisuales. Entre los mecanismos psicológicos de respuesta ante la telebasura están: la identificación con ciertos personajes, la imitación, la indirecta agudización de ciertos temas cuando son tratados de forma superficial y sin asesoría profesional, la asociación incorrecta de ciertos estímulos (ejemplo, violenciacotidianidad, mujer-objeto sexual, felicidad-consumismo, homosexualidadenfermedad, amor de pareja-sufrimiento necesario, entre otros); también, la desensibilización ante el dolor ajeno y la vulgaridad. La enorme influencia social de la TV y otros medios multiplica, de forma exponencial, los efectos negativos de este tipo de mensajes (Sartori, 2004). 
De esta forma, vemos cómo los medios de comunicación aportan a la construcción (y destrucción) de modos de ser, de modelos de comportamientos individuales y colectivos. Nos animamos a afirmar que así se van formando modelos pobres, incultos y dependientes de las sensaciones (imágenes, sonidos), descuidando los estímulos ligados al pensamiento (la razón y la lógica).

\section{La lectura como un escudo protector.}

"Lean lo que les apasione, será lo único que los ayudará a soportar la existencia"

Ernesto Sábato "La lectura es un arma de resistencia ante la animalidad"

Jorge Eslava

"No estás deprimido, estás distraído", nos avisaba el cantautor argentino Facundo Cabral. Y lo recordamos hace unos meses cuando visitamos una edición más de la Feria del libro de Lima. Hoy que se habla tanto de niños y adolescentes aburridos (y adultos también), de niños y jóvenes con problemas de atención y concentración, de personas deprimidas, me preguntaba si con tanto por leer, con tantos mundos por conocer (a través de la lectura), de pronto no es que estemos tristes - como decía Cabral- sino desatentos, distraídos, mirando hacia sitios equivocados, buscando donde no hay que buscar, mirando hoy estímulos brindados por los medios que no estimulan realmente y hasta nos empobrecen cognitiva y afectivamente (Sartori, 2004).

Alguna vez oímos la frase el dolor es inevitable, el sufrimiento es opcional. Pensamos que el sufrimiento es parte de la vida, no porque la vida sea solo pesar, sino porque hay situaciones inevitables, situaciones límite que tarde o temprano aparecerán. Por ejemplo, una enfermedad, la muerte de algún ser amado, separaciones, golpes climáticos, epidemias, crisis económicas y otras contingencias que involucra el estar vivo. Curiosamente la muerte es lo que parece darle sentido a la vida. Al saberme finito y al desconocer el día de 
mi muerte, entonces yo veo tres posibilidades: me paralizo o me desmoralizo y me estanco o (esta es la mejor) activo mi creatividad y trato de hacer algo conmigo hoy. Hoy, porque no sabré si mañana estaré vivo. Pero hoy puedo decidir vivir, aprender algo, leer, conocer a alguien, pasear, perdonar, etc. Si yo fuera eterno, o viviera 3500 años y con plena seguridad de vivir ese tiempo, me parece que mucho -o todo- sería muy aburrido, letárgico; pero es esta finitud la que me puede motivar a vivir mejor, a trabajar, a estudiar, a mejorar mis relaciones, a amar lo que hago, a evitar el dolor innecesario y a tomarme muchas cosas con sentido del humor.

La lectura es un pasatiempo enriquecedor que, de hacerse un hábito, consideramos que puede convertirse en un escudo protector de algunos de los males de la sociedad. Es una vacuna contra la estupidez, el aburrimiento, la chabacanería y el miedo. En este refugio dejamos volar nuestra imaginación, potenciamos nuestra concentración, estimulamos nuestro pensamiento y nuestras capacidades lingüísticas, además de la inteligencia general y el nivel de conocimientos.

Regresando al tema del sufrimiento, creemos que hay un sufrimiento normal, necesario, sano, inclusive del que podemos aprender algo, podemos salir más fuertes, más dignos, más fortalecidos (Frankl, 1991). También creo que hay mucho sufrimiento estéril, neurótico, estúpido, tipo telenovela. Y mucha gente no lee, pero ve telenovelas y otros programas llamados "TV basura” (Arboccó \& O’Brien, 2012).

\section{La salud mental y el sentido del humor.}

"El humor es la manifestación más elevada de los mecanismos de adaptación del individuo"

Sigmund Freud

"La potencia intelectual de un hombre se mide por la dosis de humor que es capaz de utilizar", advertía el filósofo Nietzsche (2007). Adquirir la costumbre 
de reírse de uno mismo toma algún tiempo, sobre todo cuando una persona proviene de un hogar donde esto no era frecuente, o no lo era simplemente. En el consultorio, por ejemplo, cuando un consultante (o paciente) empieza a tomarse los problemas con un poco más de calma, cuando se distancia por momentos de lo que le ocurre para mirarse en perspectiva, y cuando ya es capaz de reírse de sus tropiezos, de sus debilidades, de sus defectos y neurosis, es señal de que el proceso psicoterapéutico va dando sus frutos.

Tener sentido del humor no es exactamente ser el chistosito o la payasita del grupo. A veces, ellos solo enmascaran algún dolor, alguna insatisfacción; así, la falta de autenticidad se disfraza con una mueca o un chiste. El sentido del humor es una actitud ante la existencia, la propia y la ajena. Ante la vida misma.

La psicóloga Marta Guberman nos recuerda el poder descongestionador y purificador de la risa: "La risa tiene un efecto catártico, y percibir lo ridiculo de una situación da al hombre el distanciamiento suficiente para captarlo. El humor puede capacitar al hombre para relativizar críticamente todo tipo de experiencia o situación" (Guberman, 2013, p. 139). Esta capacidad de reírse de uno mismo y de la vida hace que el dolor no se presente tan agudo, como bien diría Víctor Hugo: "La risa es el sol que ahuyenta el invierno del rostro humano".

Todas las corrientes psicológicas actuales reconocen el valor del humor en la salud mental de las personas. El buen ánimo y el sentido del humor están ligados directamente a estados mentales como la motivación, la alegría, el rendimiento y el acercamiento social, y si lo vemos neurofisiológicamente, el cuerpo produce grandes cantidades de sustancias como la endorfina, la vasopresina y la oxitocina, todas ellas involucradas en el alivio del dolor y el aumento de la sensación del placer, además de promover la atracción, la cercanía y estimular el contacto físico. "La risa es un ejercicio valioso para 
la salud", nos informaba ya Aristóteles hace siglos, sin neurociencias en ese entonces.

Así pues, el sentido del humor es un tema importante que ya está hace tiempo siendo estudiado por las ciencias. Y, por lo visto, es cosa seria (Alemany \& Cabestrero, 2008).

\section{Enseñar para la vida: un ejemplo.}

Revisando en la web lo que ocurre en otros lugares en materia educativa, hallamos datos sobre los docentes en un país como Finlandia, donde la educación es mejor considerada que acá. Encontramos que...

Los maestros finlandeses disfrutan de un alto grado de autonomía. El currículo nacional sugiere líneas generales sobre los contenidos de las clases, pero cada comisión escolar y colegio pueden adaptar esas recomendaciones a sus condiciones particulares e, incluso, experimentar nuevos métodos. Los profesores dedican al menos dos horas semanales al perfeccionamiento, y deben participar cada año en sesiones de entrenamiento para mejorar sus competencias. (Caro, 2014, p. 1).

Toda teoría psicopedagógica debe poder adaptarse a la realidad que se tiene. Tratar de que una clase en Lima sea parecida a una en la selva o que un mismo material de trabajo se emplee por igual en Miraflores que en la serranía es un disparate. El contexto que rodea a cada quien genera demandas y propone posibilidades distintas. Siguiendo con la cita,

Al contrario de sus pares estadounidenses o noruegos, por solo citar dos ejemplos, los profesionales de la pedagogía en Finlandia desconfían de los exámenes estandarizados. Prefieren evaluaciones cotidianas, que permitan comprobar el avance de los estudiantes y adaptar la formación a las necesidades de cada uno. Y curiosamente, cuando sus discípulos participan en test internacionales, como el 
Programa Internacional para la Evaluación de Estudiantes (PISA), suelen obtener las mejores notas en el planeta, junto con otras potencias de la educación como Corea del Sur, Singapur y Japón. Además, en el currículo de las escuelas primarias, las actividades académicas tradicionales comparten el tiempo con otras no menos importantes, como las clases de arte, música, los talleres de cocina, carpintería, metalurgia y otros oficios manuales. Los finlandeses creen que durante la infancia y la adolescencia, más que cargarse con conocimientos abstractos de ciencias y humanidades, los estudiantes deben descubrir cuál es su pasión, apreciar el trabajo y crecer en armonía con sus comunidades. (Caro, 2014, p. 1).

En pocas palabras, allí, el objetivo es enseñar para la vida, mientras que nosotros seguimos enseñando temas dentro de los cursos, los cuales muchas veces no tienen ningún sentido para el estudiante, con lo que se pierden horas, se malgastan esfuerzos y se reduce el interés.

Son alentadoras las noticias que llegan desde el país de Finlandia en materia educativa. Porque lo bueno debe repetirse, debe copiarse, y si se puede mejorar, mejor aún. Estamos de acuerdo con que la educación preescolar resulta clave en el rendimiento futuro de los estudiantes, por lo que el acceso y la calidad en este nivel es una prioridad. Veamos, a los 4 y 5 años, menos de la mitad de los niños finlandeses acuden a guarderías y no empiezan el colegio sino hasta los 7 años. Sin embargo, dos años después, sus puntuaciones en la prueba PISA son mejores que el resto de los países evaluados. Parecería una contradicción, pero no. Durante los primeros seis años de la primaria, los niños tienen en todas, o en la mayoría de las asignaturas, el mismo maestro, quien vela por que ningún alumno quede excluido. Es una manera de fortalecer su estabilidad emocional y su seguridad. Hasta quinto año no hay calificaciones numéricas pues no se busca fomentar la competencia entre alumnos ni las comparaciones. La profesora Nora Bär nos cuenta que, según Pasi Sahlberg, profesor de la Universidad de Helsinki y director general del Centro para la Movilidad y la Cooperación Internacional 
de Finlandia, la "vía finlandesa" no se basa en el rigor y la competencia, sino en la colaboración, la creatividad, la igualdad de oportunidades y la formación de los educadores (Bär, 2013). Hay, entonces, una mirada grupal y cooperativa. Además, en las escuelas primarias, las actividades académicas tradicionales comparten el tiempo con otras no menos importantes, como las clases de arte, música, los talleres de cocina, carpintería, metalurgia y otros oficios manuales.

Bär señala que las clases (de grupos que no exceden los 25 alumnos) generalmente se imparten entre las 9 de la mañana y las 3 de la tarde. La escuela también provee los libros de estudio y el almuerzo, que debe cubrir un $30 \%$ de las necesidades nutricionales. Y ofrece apoyo escolar para quienes lo necesiten.

Pero lo que se considera la clave del éxito educativo finlandés son sus maestros y profesores. Elegidos entre los que obtienen los más altos promedios en la escuela secundaria, deben aprobar una maestría para estar en condiciones de ser admitidos. En ese país, de poco más de cinco millones de habitantes, la docencia es una de las profesiones más prestigiosas y, a pesar de las exigencias, atrae el interés de casi un 25\% de los estudiantes" (Bär, 2013, p. 1).

Un dato importante es que, en Finlandia, más del 90\% de los alumnos continúa estudiando y más del $50 \%$ de la población participa en programas de educación para adultos. Apenas un $8 \%$ de los alumnos finlandeses no termina sus estudios obligatorios. Notemos que la educación gratuita, desde preescolar hasta la universidad, incluye las clases, la alimentación y los materiales de estudio.

El éxito finlandés se debe a que trabajan en tres niveles: la familia, la escuela y la sociedad (Estado), propiciando recursos socioculturales (bibliotecas, ludotecas, cines). Las tres instituciones están ligadas y funcionan de forma coordinada. La familia ocupa, eso sí, el lugar central 
en el rendimiento académico de los hijos. En ese país, los padres tienen la convicción de que son los primeros responsables de la educación de sus hijos, por delante de la escuela, y ellos complementan el esfuerzo que se hace en el colegio. Nos preguntamos si, por estos lares, nuestros padres lo tienen igual de claro o si, más bien, se lavan las manos cuando de las bajas calificaciones de sus hijos hablamos. Según los reportes, en Finlandia el $80 \%$ de las familias va a la biblioteca el fin de semana. ¿Pasa igual acá?; es más, ¿en cuántas casas peruanas hay algo parecido a una biblioteca? Es para pensar y, luego, actuar.

\section{Referencias}

Aamodt, S., \& Wang, S. (2008). Entra en tu cerebro. Barcelona: Ediciones B.

Alemany, C., \& Cabestrero. R. (2008). Humor, Psicología y Psicoterapia: estudios e investigaciones en Idígoras A. (Eds.), El valor terapéutico del humor. Bilbao: Descleé de Brower.

Arboccó, M., \& O’Brien, J. (2012). Impacto de la televisión basura en la mente y la conducta de niños y adolescentes. Avances en Psicología, 2, 43-57. Recuperado de: http://www.detrasdelacortina.com.pe/download/ Impactotvbasura.pdf

Bär, N. (16 de julio de 2013). La educación en Finlandia: un modelo que asombra al mundo. La Nación. Recuperado de: http://www.lanacion. com.ar/1601467-la-educacion-en-finlandia-un-modelo-que-asombra-almundo.

Bragdon, A., \& Gamon, D. (2005). Cerebros que funcionan un poco diferente. México. Grupo Editorial Tomo.

Caro, B. L. (2014). El envidiado sistema educacional finlandés. Recuperado de: https://es-us.noticias.yahoo.com/blogs/blog-de-noticias/elenvidiado-sistema-educacional-finland\%C3\%A9s-220310805.html

Denegri, M. A. (2011). Esmórgasbord. Lima: Fondo Editorial de la Universidad Inca Garcilaso de la Vega. 
Eslava, J. (1 de marzo de 2015). La lectura en los niños. Entrevista del Diario El Comercio, Suplemento El Dominical, pp. 6-7.

Frankl, V. E. (1991). El hombre en busca de sentido. Barcelona: Editorial Herder.

García Pintos, C. (2010). La vida es una moneda. El arte de vivir. Barcelona: Plataforma Editorial.

Gil Verona, J. A. et al. (2002). Psicobiología de las conductas agresivas. Anales de Psicología, 18(2), 293-303.

González Vigil, P. (1 de marzo de 2015). Narrar para inspirar. Entrevista del Diario El Comercio, Suplemento El Dominical, p. 11.

Guberman, M. (2013). Amor, humor y autotrascendencia: los tres pilares de la relación terapéutica. Una mirada desde la logoterapia y el análisis existencial. En Relación psicoterapéutica. Enfoque fenomenológico existencial (coordinador Ramiro Gómez). Lima: Fondo Editorial de la Universidad Inca Garcilaso de la Vega.

Iacoboni, M. (2009). Las neuronas espejo. Madrid: Katz Editores.

LeDoux, J. (1999). El cerebro emocional. Argentina: Editorial Planeta.

Mesa-Gresa, P. et al. (2011). Neurobiología del maltrato infantil: "El ciclo de la violencia". Revista de Neurología, 52, 489-503.

Nietzsche, F. (2007). Estética y teoría de las artes. Madrid: Editorial Tecnos.

Santana Martínez, R. (2010). Neuropsicología para padres, maestros y especialistas en el área. Ensayo. Lima: Fondo Editorial de la Universidad Inca Garcilaso de la Vega.

Sartori, G. (2004). Homo videns. La sociedad teledirigida. España: Editorial Taurus.

Vargas Llosa, M. (2012). La civilización del espectáculo. Lima: Santillana Ediciones.

Velásquez Burgos, B. et al (2006). Teorías neurocientíficas del aprendizaje y su implicación en la construcción de conocimiento de los estudiantes universitarios. Tabula Rasa, 5, 229-245. Recuperado de: http://www. scielo.org.co/pdf/tara/n5/n5a12.pdf. 